DOI: 10.2478/linpo-2018-00010

\title{
The semantic change of positive vs. negative adjectives in Modern English
}

\author{
Abdel Rahman Mitib Altakhaineh \\ English Language Department, Al Ain University of Science and Technology, Al Ain \\ abdelrahman.takhaine@aau.ac.ae
}

\begin{abstract}
Abdel Rahman Mitib Altakhaineh. The semantic change of positive vs. negative adjectives in Modern English. The Poznan Society for the Advancement of Arts and Sciences, PL ISSN 0079-4740, pp. 25-38

This study examines two types of semantic change, namely amelioration and pejoration, through comparing the positive/negative senses of 20 English adjectives over time in the Oxford English Dictionary (OED). It also aims to explore whether the semantic change, which may have occurred in these words, can be associated with their frequency in The British National Corpus (BNC). The results reveal that the stability of the target adjectives has indeed changed over time. The positive adjectives were originally somewhat negative, neutral or positive, and then started to become positive if they were previously negative or neutral if they were previously positive. Conversely, the negative adjectives tend to become less negative over time. The study suggests that the semantic change of these adjectives could have been motivated by a tendency to reduce lexical complexity, which speakers may have done for pragmatic reasons, such as successful communication. The study also proposes that the semantic change could also be related with the frequency of the adjectives undergoing the change. The study concludes with recommendations for further research.
\end{abstract}

Keywords: lexical semantics, semantic change, amelioration, pejoration, corpora

\section{Introduction}

Since language is a communicative activity, semantic change is inevitable (Traugott 2001). Linguistic approaches to semantic change have addressed the outcome of meaning change and analysed the types of change, such as meaning broadening and narrowing, metaphoric and metonymic extension, and the developments of positive and negative meaning or what is referred to as amelioration and pejoration (Hock \& Joseph 2009; Paradis 2011; Traugott 2012, 2017 among others). Several linguists (e.g. Ullmann 1962; Blank 1999; Blank \& Koch 1999; Traugott 2001) investigated and discussed semantic change since the late nineteenth century. Discovering the motivations that trigger the change of current meaning(s) of a word from their original usage can reveal interesting aspects about human linguistic and social behaviour. Studies have shown that the change can be in one of the meanings of a word or more or even in the word's loss of meaning 
(Grondelaers et al. 2007). Every word has a variety of senses which can be changed, added to or lost over time. In fact, the entire meaning(s) of a word could have a very different sense to that of the original. An example of sense change is the change in the meaning/sense speakers have attributed to the word pretty over time. It was first used to denote 'crafty', then 'clever', and later 'attractive' (Traugott 2001). Drawing on the above, studying the semantic change of some words from present-day English seems worthy of further investigation. This paper addresses two separate aspects of positive/negative adjectives: (1) the stability over time of the negative/positive meaning of 20 English adjectives; and (2) the frequency of the target adjectives in The British National Corpus (henceforth BNC). It also aims to examine whether the semantic change, which may have occurred in these words, is related to their frequency in the BNC.

\section{Background of the study}

\subsection{Types of semantic change}

According to Ulmann (1962), several studies were conducted on the classification of types of semantic change in the first half of the twentieth century. These studies analysed the lexical or contentful change of words in isolation rather than in context. Recently, researchers (e.g. Hock \& Joseph 2009) employ more contemporary methods to examine the contexts in which the target words appear and adopt more up-to-date definitions of the various types of semantic change. Below are the definitions of the most common types of semantic change (Traugott 2017):

1. Metonymization: a process of associating words together based on contiguity. An example of this process is the metonymic shift involving part for whole, such as keel for ship.

2. Metaphorization: a process whereby one thing is conceptualized in terms of another based on similarity of sense. An example of this process is the use of tissue 'woven cloth' to conceptualize 'aggregation of cells in plants or animals'.'

3. Amelioration: a process whereby a positive meaning is associated with a word. An example from Middle English is nice which used to denote 'foolish' and now denotes 'pleasant'.

4. Pejoration: a process whereby a negative meaning is associated with a word. An example of this process is the Old English stincan 'smell either bad or sweet' and stink.

5. Generalisation: a process whereby the meaning of a word is extended. The word business can be regarded as an example of semantic generalisation since it originally meant 'the state of being busy, anxious or careworn', whereas now it denotes 'all types of work occupation'.

1 For more information on metaphors and metonymies, see Zibin \& Altakhaineh (2018). 
6. Narrowing: a process whereby the meaning of a word is restricted. An example is the Old English deor 'animal' which now denotes a specific type of animal, i.e. deer.

Ullmann (1962: 197-210) explained that the nature of the types of semantic change is different from their consequences, those are illustrated as follows:

- The narrowing of meaning results in loss of quantity.

- The widening of meaning results in rise of quantity.

- The pejoration of meaning (i.e. when the meaning of the word becomes more negative) results in loss of quality.

- The amelioration of meaning (i.e. when the meaning of the word becomes more positive) results in rise of quality.

Types of semantic change that can be described as pairs of change, such as narrowing and generalisation, or pejoration and amelioration seem to go in opposite directions, which drove some researchers to suggest that semantic change can be arbitrary and unpredictable (Wilkins 1996). According to Traugott (2017), this unpredictability arises due to the fact that the original expressions which were cited were in fact referential, which means that they can undergo changes in socio-cultural attitudes. Taking pejoration as an example; ceorl was used in the 11th century to denote 'man with low rank or without' and churl which started to be used in the 13th century to denote 'base fellow'. The impact of changes in societal roles possibly leads to the denigration of some groups of individuals as well as their jobs (Traugott 2017). Thus, it can be observed that semantic change has different motivations. The following section sheds light on the possible motivations of semantic change.

\subsection{Possible motivations of semantic change}

The motivation of semantic change is one of the hotly debated topics in linguistics (Blank 1999). Six main types of motivations for semantic change have been identified by Blank (1999: 71-81). These types are illustrated below:

1. The need for a new name (new concept): this motivation is quite self-explanatory. That is, when the world changes, our way of perceiving things also changes. This suggests that new concepts may arise as a result of such change. These new concepts can be expressed via paraphrase. However, it is more efficient to verbalise them through semantic change. An example is the word mouse which denotes 'small rodent', but now it is used to refer to the mouse used for executing commands in computer programs.

2. Abstract concepts, distant and usually invisible referents: this type of motivation is related to conceptual domains that have either abstract or distant, hard to see referents, which makes it difficult for us to understand. This abstraction yields metaphorical uses of time and emotions.

3. Sociocultural change: since language is a social behaviour, language change may take place as a result of human social interaction. In particular, social positions and the power that speakers have in their communities may give rise to changes 
in the language and by extension changes in meaning. For instance, Miller \& Napier (1993: 641) explained that in the later 19th and early 20th centuries, through establishing a public perception of equality with older professions, the nascent German audit profession endeavoured to raise its status.

4. Close conceptual or factual relation: this refers to close links between concepts which can make name transfers possible if they are efficient and they may undergo lexicalisation. Consequently, the word that has changed semantically becomes polysemous. One type of conceptual relations is the prototypical relations in which a word is continuously used to refer to the prototype of a certain category, e.g. in patriarchal societies the prototypical human being 'homo' is the man.

5. Complexity and irregularity in the lexicon: this motivation is based on the idea that speakers tend to reduce lexical irregularities and complexities in the language they use to communicate. For instance, as far as lexical complexity is concerned, when a word is used frequently, speakers attempt to reduce its significant, e.g. compounds can undergo lexical ellipsis which reduces one part of the complex word, e.g. protatile 'portable'< computer portatile 'notebook computer'.2

6. Emotionally marked concepts: in order to express concepts that are marked emotionally such as death, euphemistic expressions can be used. Blank (1991: 81) indicated that euphemistic expressions can be used to avoid jeopardizing the success of communicative interactions where the interlocutor's feeling can be offended. Thus, in the case of death, rather than saying that someone died, one can say passed away.

It can be observed that one of the primary motivations for semantic change pertains to speakers' pragmatic goals. In particular, speakers aim to obtain, achieve or exert influence which requires successful communication. As Blank (1999) puts it, change takes place since, when we use language; it is "a consequence of inherent characteristics of man's mind and human social interaction" (Blank 1999: 63). Having discussed the motivations for semantic change, the following section provides examples of semantic change.

\subsection{Instances of semantic change}

An example of a semantic change is what occurred with the word awful. According to Stockwell \& Minkova (2001: 157), the original meaning of awful was 'full of awe' as in the example: the awful majesty of the Creator. However, following that, awful has started to denote something which is extremely bad as in the example: an awfully bad performance. At present, the intensity of the word has decreased, so it is used now informally to denote 'very bad' e.g. an awful mess (Stockwell \& Minkova ibid).

In another recent study, Hollmann (2009: 301) investigated some instances of how words such as very and silly undergo a change in meaning. The change detected can be considered remarkable since silly used to denote 'blessed' or 'blissful'. However, the meaning of silly has changed markedly into 'foolish'. Since there is a significant gap in

${ }^{2}$ For more information on English compounds, see Lieber \& Štekauer (2009) and Altakhaineh (2016). 
meaning between 'blessed' and 'foolish', it has been argued that the meaning of the word silly must have passed through intermediate stages (Hollmann ibid). Based on The Oxford English Dictionary (henceforth OED), it has been observed that the earliest recorded instances of the word silly took place c1200. Additionally, Hollmann (2009: 306) indicates that in the first one hundred years, the meaning of silly was 'blessed' or 'blissful'. Through examining the second instance of the word silly, it has been found that the next stage, towards the end of the thirteenth century, introduced the meaning 'harmless' or 'innocent'. Following that, the meaning has undergone another change, becoming 'deserving of pity or sympathy'. After that, another change was observed, where the word silly started to denote 'weak/feeble', pertaining to physical strength. In the final stage, which took place in the sixteenth century, the meaning 'foolish' was introduced. One may observe that during the different stages through which the word silly has passed, it has changed from the positive 'blessed' or 'blissful' (in the Middle Ages) into something that tends to be negative i.e. 'foolish'. It is important to note here that the change as a whole is remarkable. However, the individual steps are not. 'Blessed/blissful' is not very different from 'harmless/innocent' since blessed people and things, especially in the medieval mentality, are usually harmless and innocent as well and vice versa. Due to the overlap between the category of people and things characterised as being 'harmless/innocent' and those considered 'blessed/blissful', speakers could have re-interpreted the utterances they heard. For instance, a blessed religion could have been re-interpreted as a harmless one.

Against this background, this study falls within a linguistic trend which aims to investigate the semantic change that may have taken place in certain English adjectives as far as their negative/positive meanings are concerned. Understanding such change may shed light on human linguistic and social behaviour over time (see Blank 1999; Traugott 2001, 2017). Specifically, the current study seeks answers to the following research questions:

1. To what extent has the meaning of 20 English adjectives changed over time in the OED in relation to the stability of their positive and negative meaning?

2. Does their frequency in the BNC have an impact on their semantic change?

The following section presents and discusses the methodology adopted in the current study.

\section{Methodology}

\subsection{Sample}

Twenty adjectives, 10 adjectives with positive meanings and another 10 with negative ones were chosen based on their frequency in the BNC. That is, I conducted a cursory analysis of 50 randomly-selected English adjectives, checking their frequency in the BNC. This analysis has yielded the 20 target adjectives investigated in this study. The BNC was later used to further examine the frequency of the target adjectives in present-day English (see section 3.2). The current meaning of the target words was checked in the OED and by three native speakers of English for objectivity. The words are commonly 
used and none of them is hapax. Each word has been used, at least, 80 times based on an automated search of The British National Corpus (henceforth, the BNC). Table 1 lists the target adjectives.

Table 1: The target adjectives in the study

\begin{tabular}{rll}
\hline No. & \multicolumn{1}{c}{$\begin{array}{c}\text { Adjectives with } \\
\text { positive meanings }\end{array}$} & \multicolumn{1}{c}{$\begin{array}{c}\text { Adjectives with } \\
\text { negative meanings }\end{array}$} \\
\hline 1. & excellent & abominable \\
2. & amazing & abysmal \\
3. & brilliant & abhorrent \\
4. fabulous & appalling \\
5. & wonderful & atrocious \\
6. & fantastic & disgusting \\
7. & awesome & dreadful \\
8. & magnificent & ghastly \\
9. & spectacular & horrendous \\
10. & marvellous & terrible \\
\hline
\end{tabular}

\subsection{Tools}

For the purpose of this study, two sources were used. The first source is the OED since it is the main historical dictionary of English published by Oxford University Press. It traces the historical development of English words over time, providing an invaluable source for linguists and scholars interested in language change (Baugh \& Cable 1993). As a result, the OED was used to investigate the stability of the meaning of the target adjectives over time. Additionally, according to Hollmann (2009), the OED comprises etymological information, which can help linguists trace the origin of English words. The second source is the BNC; this source was used to filter the target adjectives based on their frequency. The BNC is a valuable source that can be used to examine the frequency of words in present-day English; words may have been more or less frequent in the past than today (see Hundt \& Mair 1999; Stubbs 2001; Leech \& Rayson 2014 among others).

\subsection{Calculations of frequency}

By adopting a quantitative approach, a simple equation was used to calculate the frequency of the target positive/negative adjectives. Firstly, it was taken into account that some adjectives e.g. great can have a neutral meaning, as in a great effort, a great deal of and a great amount of money. Secondly, I inspected a random sample of 25 instances of each adjective used in the study, and checked the BNC to determine how many of 
those words are positive, negative or neutral. For instance, let us assume that among the 25 examples of the word great, there were 15 instances in which it has a clearly positive meaning and 10 where it has a neutral or not so clear meaning. The percentage in this case can be expressed as follows:

(1) 15 positive meanings/ 25 total of inspected instances $=60 \%$ with positive meaning

Following that, I obtained the total frequency of the word great (let us say 5000). Using the percentage I have already got on the 25 examples in order to estimate how many positive examples of great there are in the BNC, the result would be $60 \%$ of 5000 $=3000$. This method was applied to all words in the study. However, one limitation of this study is that it investigates only 20 adjectives in total. Therefore, the results of this study need to be interpreted with caution since it would not be reasonable to generalise at this point. The results of this study are presented and discussed in the following section.

\section{Discussion and results}

This section tackles two issues: in sections 4.1, the stability of the negative/positive meaning of the target adjectives are examined over time, and in section 4.2, their frequency in the BNC is explored, and the correlation between the semantic change, which the target words may have undergone, and their frequency in the BNC is explained.

\subsection{The stability of the meaning of the adjectives overtime}

Table 2 shows the meaning of the positive adjectives in the OED overtime, and Table 3 presents the meaning of the negative adjectives.

Table 2: The positive adjectives and their meaning in the OED over time

\begin{tabular}{|c|c|c|}
\hline No & $\begin{array}{l}\text { Words with } \\
\text { positive meanings }\end{array}$ & Examples of meanings from the OED over time \\
\hline 1. & excellent & $\begin{array}{l}\text { c1384 to c1744 with 'Of a person or thing: That excels or surpass- } \\
\text { es in any respect; preëminent, superior, supreme. Of qualities: } \\
\text { Existing in a greater, or an exceptionally great, degree.' } \\
1609 \text { to } 1821 \text {, 'Used as an emphatic expression of praise or } \\
\text { approval, whether of persons, things, or actions: Extremely good.' }\end{array}$ \\
\hline 2. & amazing & $\begin{array}{l}\text { c1597 to c1781 with 'Causing distraction, consternation, confusion, } \\
\text { dismay; stupefying, terrifying, dreadful. Obs.' } \\
\text { c1704 to c1849 with 'Astounding, astonishing, wonderful, great } \\
\text { beyond expectation.' }\end{array}$ \\
\hline 3. & brilliant & $\begin{array}{l}1681 \text { to } 1878 \text { 'Brightly shining, glittering, sparkling, lustrous.' } \\
1971 \text { to } 1984 \text { 'In weakened use: amazing, fantastic. ' }\end{array}$ \\
\hline
\end{tabular}


4. fabulous

1551 to 1864 'Of a person (or anything personified): Fond of relating fables or legends, given to fabling.'

1609 to 1963 'Such as is met with only in fable; beyond the usual range of fact; astonishing, incredible.'

5. wonderful

a1100 to 1884 'Full of wonder; such as to excite wonder or astonishment; marvellous; sometimes used trivially = surprisingly large, fine, excellent, etc.'

c1380 to 1583 'Filled with wonder or admiration.'

6. fantastic

a1387 to 1742 'Existing only in imagination; proceeding merely from imagination; fabulous, imaginary, unreal.'

1493 to 1702 'Fanciful, impulsive, capricious, arbitrary; also, foppish in attire. Now in stronger sense: Extravagantly fanciful, odd and irrational in behaviour.'

1938 to 1987 'In trivial use: excellent, good beyond expectation.'

7. awesome 1598 to 1880 'Full of awe, profoundly reverential.'

1961 to 1986 'In weakened sense: overwhelming, staggering; remarkable, prodigious.'

1980 to 1986 'In trivial use, as an enthusiastic term of commendation: 'marvellous', 'great'; stunning, mind-boggling.'

8. magnificent a1460 to 1987 'Of an immaterial thing: imposing, exalted, sublime' 1603 to 1889 'Proud, haughty; arrogantly ambitious.'

1533 to 1987 'Sumptuously constructed or decorated. Also, in wider sense: imposingly beautiful, splendid.'

1664 to 1981 'Used to express enthusiasm or admiration: excellent, splendid, fine.'

9. spectacular 1682 to 1934 'Of the nature of a spectacle or show; striking or imposing as a display.'

1890 to 1978 'As n. A spectacular display; also spec. a radio or television programme, entertainment, etc., produced on a lavish or spectacular scale.'

10. marvellous c1330 to 1994 'Such as to excite wonder or astonishment (chiefly in a positive sense); wonderful, astonishing, surprising; worthy of admiration. Also (esp. from the later ME. period until 16th cent.): having remarkable or extraordinary (and as if supernatural) properties.'

1868 to 1999 'In weakened sense (formerly sometimes regarded as an affectation in speech): extremely good or pleasing; splendid.' 
Table 3: The negative adjectives and their meaning in the OED over time

\begin{tabular}{|c|c|c|}
\hline No. & $\begin{array}{c}\text { Words with } \\
\text { positive meanings }\end{array}$ & Examples of meanings from the OED over time \\
\hline 1. & abominable & $\begin{array}{l}1340 \text { to } 2003 \text { 'That excites moral or physical revulsion or disgust; } \\
\text { offensive, reprehensible; loathsome, odious, detestable.' } \\
1612 \text { to } 1992 \text { 'In weakened sense: very unpleasant or distasteful; } \\
\text { dreadful, terrible.' }\end{array}$ \\
\hline 2. & abysmal & $\begin{array}{l}1656 \text { to } 1976 \text { 'Of, relating to, or resembling an abyss; bottomless; } \\
\text { profound; spec.: of, resembling, or relating to Hell; hellish.' } \\
1904 \text { to } 2010 \text { 'Of an exceptionally poor standard or quality; ex- } \\
\text { tremely bad, appalling.' }\end{array}$ \\
\hline 3. & abhorrent & $\begin{array}{l}1599 \text { to } 1790 \text { 'That shrinks or recoils with repugnance from something.' } \\
1604 \text { to } 1903 \text { 'Far removed in respect of nature or character, } \\
\text { estranged, greatly divergent from something' } \\
1628 \text { to } 2008 \text { 'Repugnant; hateful, detestable; abhorred.' }\end{array}$ \\
\hline 4. & appalling & $\begin{array}{l}1817 \text { to } 1836 \text { 'Such as to overwhelm with consternation or dismay; } \\
\text { dismaying, shocking.' } \\
1919 \text { to } 1985 \text { 'colloq. In weakened sense: distasteful, 'shocking' }\end{array}$ \\
\hline 5. & atrocious & $\begin{array}{l}1669 \text { to } 1839 \text { 'Characterized by savage enormity; excessively and } \\
\text { wantonly cruel; heinously wicked' } \\
\text { In } 1885 \text {, 'colloq. Very bad, shocking, execrable' }\end{array}$ \\
\hline 6. & disastrous & $\begin{array}{l}1586 \text { to } 1790 \text { 'Stricken with or subject to disasters; ill-starred, ill-fat- } \\
\text { ed; unfortunate, unlucky.' } \\
1603 \text { to } 1875 \text { 'Of the nature of a disaster; fraught or attended with } \\
\text { disaster; calamitous.' }\end{array}$ \\
\hline & horrible & $\begin{array}{l}1303 \text { to } 1871 \text { 'Exciting or fitted to excite horror; tending to make } \\
\text { one shudder; extremely repulsive to the senses or feelings; dreadful, } \\
\text { hideous, shocking, frightful, awful.' } \\
\text { a1464 to } 1718 \text { 'as a strong intensive (now colloq.): Excessive, } \\
\text { immoderate. (Primarily of things objectionable, but often without } \\
\text { such qualification.' } \\
\text { c1540 to } 1917 \text { 'A horrible person or thing; †a being inspiring awe } \\
\text { or dread (quot. c1475 at sense C.); a horrible attribute or character- } \\
\text { istic; a story of horrible crime or the like.' }\end{array}$ \\
\hline 8. & ghastly & $\begin{array}{l}\text { c1305 to } 1888 \text { 'Causing terror, terrible (obs.). In mod. use (cf. } 2 \text { ): } \\
\text { Suggestive of the kind of horror evoked by the sight of death or } \\
\text { carnage; horrible, frightful, shocking.' } \\
1860 \text { to } 1969 \text { 'Said hyperbolically of persons or things objectionable } \\
\text { on various grounds: Shocking, 'frightful'.' }\end{array}$ \\
\hline 9. & horrendous & 1661 to 1972 'fitted to excite horror; terrible, dreadful, horrible.' \\
\hline 10. & terrible & $\begin{array}{l}\text { c1400 to } 2009 \text { 'Causing or fit to cause terror; inspiring great fear or } \\
\text { dread. Also: awe-inspiring, awesome.' } \\
1509 \text { to } 2008 \text { 'Very harsh, severe, or painful; formidable; very difficult.' } \\
1775 \text { to } 2007 \text { 'Exceedingly incompetent; of shockingly poor perfor- } \\
\text { mance or quality.' }\end{array}$ \\
\hline
\end{tabular}


An examination of Table 2 shows that the positive adjectives started with: (1) somewhat negative; (2) neutral; or positive meanings, and then started to become positive if they were negative before or neutral if they were positive before. An example of the first case is the word amazing, which started to be used in c1597 to c1781 with the meaning: 'Causing distraction, consternation, confusion, dismay; stupefying, terrifying, dreadful'. However, from c1704 to c1849, the meaning has changed, becoming positive i.e. 'Astounding, astonishing, wonderful, great beyond expectation.' This process in which the meaning of the word becomes more positive overtime is called amelioration (Ullmann 1962). An example of the second case is the word fantastic, which was used in a neutral sense from 1387 to 1742 i.e. 'Existing only in imagination; proceeding merely from imagination; imaginary, unreal'. In contrast, between 1938 and 1987, fantastic has started to be used in a positive sense i.e. 'excellent, good beyond expectation'. Finally, an example of the third case in which the word started out as being positive, then its intensity has lessened overtime is the word marvellous. From c1330 to 1994, marvellous used to mean; 'Such as to excite wonder or astonishment (chiefly in a positive sense); wonderful, astonishing, surprising; worthy of admiration'. However, from 1868 to 1999, the intensity of the word has decreased; it started to mean: 'in weakened sense: extremely good or pleasing; splendid.'

Table 3 shows that the negative adjectives tend to become less negative over time. For instance, the word atrocious from 1669 to 1839 used to denote savage enormity, cruelty and wickedness. However, through time, that meaning has become less negative. Specifically, in 1885, atrocious has started to be used colloquially to denote 'very bad, shocking or execrable' (cf. awful in Stockwell \& Minkova 2001). Another example is the word ghastly, from c1305 to 1888 , it was used to denote: 'Causing terror, terrible, suggestive of the kind of horror evoked by the sight of death or carnage; horrible, frightful, shocking.' However, from 1860 to 1969, the intensity of the word lessened over time, denoting: 'Said hyperbolically of persons or things objectionable on various grounds: Shocking, 'frightful'. It can be suggested, here, that the semantic change some of these adjectives have undergone, e.g. marvellous and ghastly can be attributed, in part, to motivations of change related to reducing lexical complexities. As discussed in section 2.2, Blank (1999) proposed that in several cases, semantic change was triggered by the tendency of speakers to limit lexical complexities in order to communicate successfully with others. In fact, speakers' pragmatic concerns were regarded as an important motivation for different types of semantic change. From another perspective, it was also suggested by Blank (1999) that when a word is used frequently, speakers attempt to reduce its significant and intensity. Thus, it can be argued that the change in the meaning of the target adjectives overtime could be correlated with the frequency of adjectives undergoing the change. This notion is explored in the following section. 


\subsection{The frequency of the positive/negative meanings of the adjectives in present-day English}

In this section, the frequency of the target adjectives is compared in the BNC to determine whether their meaning is positive or negative in present-day English. Table 4 shows the percentage and frequency of the adjectives with positive meanings.

Table 4: The percentage and frequency of 10 adjectives with positive meanings

\begin{tabular}{lccc}
\hline $\begin{array}{l}\text { No. Adjectives with } \\
\text { positive meanings }\end{array}$ & $\begin{array}{c}\text { The total frequency } \\
\text { of the adjective in } \\
\text { BNC }\end{array}$ & $\begin{array}{c}\text { Percentage of the } \\
\text { positive meaning }\end{array}$ & $\begin{array}{c}\text { The total number of } \\
\text { positive meanings in } \\
\text { BNC }\end{array}$ \\
\hline $\begin{array}{l}\text { 1. excellent } \\
\text { 2. amazing }\end{array}$ & 6611 & $64 \%$ & 4231 \\
3. brilliant & 3411 & $60 \%$ & 1115 \\
4. fabulous & 678 & $68 \%$ & 2320 \\
5. wonderful & 4659 & $88 \%$ & 597 \\
6. fantastic & 1136 & $80 \%$ & 3727 \\
7. awesome & 368 & $72 \%$ & 280 \\
8. magnificent & 1970 & $76 \%$ & 1497 \\
9. spectacular & 1925 & $76 \%$ & 1413 \\
10. marvellous & 1766 & $84 \%$ & 1617 \\
\hline
\end{tabular}

Table 4 demonstrates that the target words in this study are used positively in the BNC but with different degrees. That is, a number of the adjectives are used in a neutral sense rather than a positive one. For instance, $88 \%$ of the instances of fabulous are positive, whereas $64 \%$ of those of excellent are positive. It can be argued that there is a correlation between the frequency of the adjective and the stability of its meaning over time. Specifically, adjectives which are more frequent are more susceptible to a change in meaning, whilst those which are less frequent are not. In other words, adjectives which are used less frequently may preserve their meaning through time as a result of lack of usage compared to other words. Table 4 shows that the word excellent is used 6611 times in the BNC, whereas the word fabulous is only used 678.

Additionally, even though words such as amazing is used in a positive sense in present-day English (60\%), the fact that it used to have a negative meaning in the past may 
have still affected its use in recent years. In this study, it was difficult to determine whether amazing is used in a positive sense, a neutral or a negative sense. A reminiscent of its past use could still be there, decreasing the degree of its positivity and making it neutral in many cases in the BNC.

Table 5: The percentage and frequency of 10 adjectives with negative meanings

\begin{tabular}{cccc}
\hline $\begin{array}{c}\text { No. } \begin{array}{c}\text { Adjectives with } \\
\text { negative mean- } \\
\text { ings }\end{array} \\
\text { 1. abominable }\end{array}$ & $\begin{array}{c}\text { The total frequency of } \\
\text { the adjective in BNC }\end{array}$ & $\begin{array}{c}\text { Percentage of the ad- } \\
\text { jective with negative } \\
\text { meaning }\end{array}$ & $\begin{array}{c}\text { The total number of the } \\
\text { adjective with negative } \\
\text { meanings in BNC }\end{array}$ \\
2. abysmal & 86 & $84 \%$ & 72 \\
3. abhorrent & 65 & $76 \%$ & 65 \\
4. appalling & 1026 & $88 \%$ & 698 \\
5. atrocious & 118 & $68 \%$ & 71 \\
6. disastrous & 1110 & $60 \%$ & 799 \\
7. dreadful & 1362 & $72 \%$ & 926 \\
8. ghastly & 398 & $68 \%$ & 2673 \\
9. horrendous & 301 & $80 \%$ & 265 \\
10. terrible & 4455 & $80 \%$ & $26 \%$ \\
\hline
\end{tabular}

Table 5 shows that the negative adjectives examined in this study are used in a negative sense but with different degrees. Through examining their meanings in the OED, it can be observed that their intensity is decreasing through time. While investigating the instances of the target words in the $\mathrm{BNC}$, it can be detected that their intensity is becoming less and less. This could be related to their frequency in the BNC. That is, it seems that the intensity of the words which are more frequent is decreasing over time, whereas that of the words which are less frequent remains stable. For example, $88 \%$ of the instances of the word abhorrent in the BNC are negative, whereas only $60 \%$ of those of the word terrible are negative. The reason for this difference could be due to their frequency in the BNC. In particular, terrible is used 4455 times, whilst abhorrent is only used 66 times.

Thus, to provide answers to the two research questions, it seems that the stability of the positive/negative meanings of the target adjectives has changed overtime. For instance, the meaning of positive adjectives was originally negative, neutral, or positive, to some 
extent, and then began to become positive if they were previously negative or neutral if they were previously positive. It was proposed that the semantic change could have been motivated by a tendency to reduce lexical complexities or could be related to the frequency of the target adjectives in the BNC. However, it should be noted that the results of this study cannot be considered definitive due to the low number of adjectives examined. However, it is hoped that this study is nevertheless worthwhile in providing an initial exploration of the two research questions.

\section{Conclusion}

This study has examined the stability of the positive/negative meaning of 20 English adjectives in the OED. It has also explored the notion that any semantic change which may have taken place in the target adjectives could be related to the frequency of these words in the BNC. The results revealed that the positive adjectives were originally somewhat negative, neutral or positive, and then started to become positive if they were previously negative or neutral if they were previously positive. On the other hand, the negative adjectives tend to become less negative over time. It was argued that the change in meaning overtime could have been triggered by a tendency to reduce lexical complexity which speakers may have done for pragmatic reasons such as successful communication. It was also suggested that the semantic change could also be correlated with the frequency of the adjectives undergoing the change. That is, the most frequent adjectives, both with positive or negative meanings, seem to change their meanings over time, whereas the meaning of the less frequent adjectives tends to remain stable. The positive adjectives remain positive or they become more neutral, whereas the intensity of negative words seems to decrease overtime. Following the same method used in this study, it is recommended that more data needs to be collected and analysed to confirm or falsify the results obtained in this study.

\section{References}

Altakhaineh, Abdel R. M. 2016. What is a compound? The main criteria for compoundhood. ExELL 4(1). 58-86.

Baugh, Albert C. \& Cable, Thomas. 1993. A History of the English Language. London: Routledge.

Blank, Andreas. 1999. Why do new meanings occur? A cognitive typology of the motivations for lexical Semantic change. In Blank, Andreas \& Koch, Peter (eds.), Historical Semantics and Cognition, 61-90. Berlin, New York: Mouton de Gruyter.

Blank, Andreas \& Koch, Peter. 1999. Introduction: Historical semantics and cognition. In Blank, Andreas \& Koch, Peter (eds.), Historical Semantics and Cognition, 1-16. Berlin, New York: Mouton de Gruyter.

BNC. 1991-2007. The British National Corpus. Managed by the BNC Consortium, an industrial/academic consortium led by Oxford University Press. Compilation of 100 million words.

Grondelaers, Stefan \& Speelman, Dirk \& Geeraerts, Dick. 2007. Lexical variation and change. In Geeraerts, Dick \& Cuyckens, Hubert (eds.), The Oxford Handbook of Cognitive Linguistics, 988-1011. New York: Oxford University Press.

Hock, Hans H. \& Joseph, Brian D. 2009. Language History, Language Change, and Language Relationship: An Introduction to Historical and Comparative Linguistics. Berlin: Mouton de Gruyter. 
Hollmann, W. 2009. Semantic change. In Culpeper, Jonathan \& Kerswill, Paul \& Wodak, Ruth \& McEnery, Anthony \& Katamba, Francis (eds.), English Language: Description, Variation and Context, 301-313. Basingstoke: Palgrave.

Hundt, Marianne \& Mair, Christian. 1999. "Agile" and "Uptight" Genres: The Corpus-based Approach to Language Change in Progress. International Journal of Corpus Linguistics 4(2). 221-242.

Leech, Geoffrey \& Rayson, Paul \&Wilson, Andrew. 2014. Word Frequencies in Written and Spoken English: Based on the British National Corpus. London: Routledge.

Lieber, Rochelle \& Štekauer, Pavol. 2009. Introduction: Status and definition of compounding. In Lieber, Rochelle \& Štekauer, Pavol (eds.), The Oxford Handbook of Compounding, 3-18. Oxford: Oxford University Press.

Miller, Peter \& Napier, Christopher. 1993. Genealogies of Calculation. Accounting, Organizations and Society 18(7/8). 631-647.

OED. 1868-2018. The Oxford English Dictionary. Oxford: Oxford University Press.

Paradis, Carita. 2011. Metonymization: A key mechanism in semantic change. In Benczes, Réka \& Barcelona, Antonio \& Ruis de Mendoza Inbáñez, Francisco J. (eds.), Defining metonymy in cognitive linguistics: Toward a consensus view, 61-88. Amsterdam: Benjamins.

Stockwell, Robert P. \& Minkova, Donka. 2001. English Words: History and Structure. Cambridge: Cambridge University Press.

Stubbs, Michael. 2001. Words and Phrases: Corpus Studies of Lexical Semantics. Oxford: Blackwell Publishers.

Traugott, Elizabeth. 2017-03-29. Semantic Change. Oxford Research Encyclopedia of Linguistics. http://linguistics.oxfordre.com/view/10.1093/acrefore/9780199384655.001.0001/acrefore-9780199384655-e-323. (Accessed 2018-06-06)

Traugott, Elizabeth C. 2012. Linguistic levels: Semantics and lexicon. In Bergs, Alexander \& Brinton, Laurel J. (eds.), English Historical Linguistics: An International Handbook, 164-177. Berlin: De Gruyter Mouton.

Traugott, Elizabeth C. \& Dasher, Richard B. 2001. Regularity in Semantic Change. Cambridge: Cambridge University Press.

Ullmann, Stephen. 1962. Semantics: An Introduction to the Science of Meaning. Oxford: Blackwell.

Wilkins, David P. 1996. Natural tendencies of semantic change and the search for cognates. In Durie, Mark \& Ross, Malcolm (eds.), The Comparative Method Reviewed: Regularity and Irregularity in Language Change, 264-304. New York: Oxford University Press.

Zibin, Aseel \& Altakhaineh, Abdel R. M. 2018. An analysis of Arabic metaphorical and/or metonymical compounds. Metaphor and the Social World 8(1). 100-133. 